\title{
ANALISIS KINERJA INSTALASI FARMASIRUMAH SAKIT X PURWOKERTODITINJAU DARI PERSPEKTIF CUSTOMER BALANCED SCORECARD "KETERJARINGAN PASIEN"
}

\author{
Fithria Dyah Ayu $\mathrm{S}^{1^{*}}$, Satibi ${ }^{2}$, Achmad Fudholi ${ }^{2}$ \\ ${ }^{1}$ Program Studi Profesi Apoteker Universitas Islam Indonesia \\ ${ }^{2}$ Fakultas Farmasi Universitas Gadjah Mada \\ *email: fithria.ayu@gmail.com
}

\begin{abstract}
ABSTRAK
IFRS X Purwokerto merupakan salah satu rumah sakit pemerintah sebagai pelayanan publik. Pengelolaan keuangan IFRS X Purwokerto dikelola dengan sistem Badan Layanan Umum. Persentase pasien memiliki dampak terhadap pendapatan rumah sakit. Persentase pasien adalah salah satu pengukuran perspektif pelanggan pada metode balanced scorecard. Desain penelitian yang digunakan adalah studi kasus deskriptif. Data kuantitatif diperoleh dari dokumen penerimaan rawat jalan pada Desember 2008, dan dari data administrasi rumah sakit. Data kualitatif diperoleh dari wawancara dengan Kepala Departemen Farmasi Rumah Sakit X Purwokerto. Data kuantitatif dianalisis sebagai rata-rata persentase pasien yang dihadapi, dan data kualitatif adalah deskriptif analisis. Hasil menunjukkan rata-rata persentase pasien yang ditemui pada pasien rawat jalan IFRS $X$ Purwokerto adalah 71,84\%. Kepala Departemen Farmasi Rumah Sakit $X$ Purwokerto mengatakan untuk mengoptimalkan persentase pasien perlu kerjasama semua segmen, dari stakehoulders (direktur dewan rumah sakit $X$ Purwokerto dan pemerintah), dan perbaikan terus-menerus dari proses internal IFRS $X$ Purwokerto.
\end{abstract}

Kata kunci: IFRS X, perspektif pelanggan, Purwokerto, persentase pasien yang dihadapi
ABSTRACT

IFRS $X$ Purwokerto is one of government's hospital as a public services. The financial management of IFRS $X$ Purwokerto managed with Badan Layanan Umum system. The percentage of patients encountered has impacts to the hospitals revenue. The percentage of encountered patients is one of the customer perspective measurement on balanced scorecard methods. The researh design was descriptive case study. Quantitative data were obtained from outpatient receipts document on December 2008, and from hospital administrative data. Qualitative data were obtained from depthr interview with Head of Pharmacy Department X Hospital Purwokerto. Quantitative data were analyzed as a mean of percentage of patients encountered, and qualitative data was descriptive analyzed. Result shown the mean of percentage of patients encountered in outpatients IFRS $X$ Purwokerto was $71,84 \%$. The Head of Pharmacy Department $X$ Hospital Purwokerto was said in order to optimizing the percentage of patients encountered, need cooperation all segment, from the stakehoulders (board directors of hospital X Purwokerto and the government), and continous improvement of internal process in IFRS X Purwokerto.

Keywords: customer perspective, IFRS $X$ Purwokerto, percentage of patients encountered 


\section{PENDAHULUAN}

IFRS $X$ Purwokerto merupakan salah satu IFRS milik pemerintah yang bertanggung jawab atas pelayanan publik. IFRS $X$ Purwokerto merupakan unit pelaksana fungsional yang bertanggung jawab dalam kendali mutu pelayanan kefarmasian, baik dalam hal perbekalan farmasi maupun pelayanan farmasi klinis (Anonim, 1999). IFRS X Purwokerto memiliki 2 (dua) jenis pelayanan, yaitu pelayanan rawat jalan dan pelayanan rawat inap. Pelayanan rawat jalan terbagi ke dalam rawat jalan umum dan rawat jalan ASKES.

IFRS $X$ Purwokerto merupakan salah satu organisasi jasa yang tidak dapat terlepas dari kompetisi lingkungan. Hal tersebut disebabkan karena lingkungan bisnis di berbagai industri bersifat turbulen dan kompetitif. Turbulen dalam arti perubahan yang cepat, radikal, dan pervasif, sedangkan kompetitif karena keberadaan kompetitor (pesaing) yang banyak di berbagai industri yang ada. Pengaruh lingkungan yang kompetitif memacu organisasi untuk memiliki kapabilitas dalam memenangkan pilihan pelanggan, organisasi harus melakukan continuous improvement (perbaikan yang terus menerus), dan harus mampu menjadi wealth multiplying organization (Mulyadi, 2008). Keputusan Menteri Kesehatan Republik Indonesia Nomor 1197/Menkes/SK/X/2004 tentang Standar Pelayanan Farmasi di Rumah Sakit menyatakan bahwa perlu evaluasi secara periodik terhadap konsep, kebutuhan, proses, dan hasil, sehingga dapat meningkatkan mutu pelayanan kefarmasian. Evaluasi terhadap proses dan hasil dari
IFRS X Purwokerto dapat dilakukan dengan menggunakan balanced scorecard.

Balanced scorecard merupakan alat pengukuran kinerja yang diperkenalkan oleh Kaplan dan Norton (1996). Balance diartikan bahwa pengukuran kinerja yang dilakukan bersifat setimbang, yaitu pengukuran kinerja keuangan dan nonkeuangan, serta pengukuran kinerja jangka pendek dan jangka panjang. Scorecard berarti kartu yang digunakan untuk mengukur skor kinerja (Mulyadi, 2008). Sistem pengukuran kinerja memungkinkan perusahaan untuk dapat melakukan perencanaan, pengukuran, dan evaluasi terhadap kinerja yang disesuaikan dengan strategi yang telah dibangun sejak awal (Okwo, Marire, 2012). Hasil penelitian Kairu, et al, 2013 menunjukkan bahwa pengukuran kinerja nonkeuangan memiliki kedudukan yang sama penting dengan pengukuran kinerja keuangan, dan integrasi kedua sistem pengukuran kinerja dapat diperoleh hasil yang superior. Balanced scorecard melakukan pengukuran kinerja berdasarkan pada 4 (empat) perspektif, yaitu perspektif keuangan, perspektif pelanggan (customer), perspektif proses bisnis internal, dan perspektif pertumbuhan dan pembelajaran (Mulyadi, 2005).

Salah satu pengukuran kinerja perspektif pelanggan (customer) adalah pengukuran tingkat keterjaringan pelanggan. Tingkat keterjaringan pasien yang tinggi akan meningkatkan pendapatan rumah sakit, demikian pula sebaliknya. Tingkat keterjaringan pasien mengukur proporsi jumlah resep yang terlayani atau ditebus di IFRS $X$ Purwokerto dibandingkan dengan jumlah pasien yang mendapatkan resep dalam periode hari yang sama. 


\section{METODE PENELITIAN}

Rancangan penelitian adalah studi kasus yang bersifat deskriptif, dengan pengambilan data kuantitatif maupun kualitatif. Pengambilan data kuantitatif didapatkan dari survai resep pasien rawat jalan, baik rawat jalan umum maupun rawat jalan ASKES (Asuransi Kesehatan), serta data jumlah pasien yang mendapatkan resep dari masing-masing poliklinik di rumah sakit selama Bulan Desember 2008. Pengambilan data kualitatif didapatkan dengan wawancara mendalam dengan Kepala IFRS $X$ Purwokerto.

Analisa data kuantitatif dilakukan dengan menghitung rata-rata proporsi jumlah resep yang terlayani oleh instalasi rawat jalan IFRS $X$ Purwokerto dibandingkan dengan jumlah pasien yang mendapatkan resep dari masing-masing poliklinik di rumah sakit. Analisa data kualitatif dilakukan dengan mendeskripsikan hasil wawancara mendalam dengan Kepala IFRS $X$ Purwokerto.

\section{HASIL DAN PEMBAHASAN}

Instalasi farmasi rawat jalan di IFRS $X$ Purwokerto terbagi menjadi 2 (dua) bagian, yaitu satelit farmasi rawat jalan umum, dan satelitrawat jalan ASKES. Pasien yang dilayani di Instalasi farmasi rawat jalan umum adalah pasien yang membayar sendiri (out of pocket) atau tidak tercover oleh asuransi, sedangkan pasien yang dilayani dalam satelit farmasi rawat jalan ASKES adalah pasien dengan asuransi dari ASKES, Jamkesmas (Jaminan kesehatan masyarakat), Jamsostek (Jaminan sosial tenaga kerja) ataupun asuransi perusahaan yang bekerja sama dengan rumah sakit. Hasil keterjaringan pasien di satelit farmasi rawat jalan umum adalah:

Tabel I. Data Keterjaringan Pasien Rawat Jalan Umum di IFRS X Purwokerto

\begin{tabular}{|c|c|c|c|}
\hline Tgl & $\begin{array}{c}\text { Jumlah resep yang } \\
\text { dilayani (A) }\end{array}$ & $\begin{array}{l}\text { Jumlah pasien yang mendapatkan } \\
\text { resep (B) } \\
\end{array}$ & $\%(\mathrm{~A} / \mathrm{Bx} 100)$ \\
\hline 1 & 112 & 153 & $73,20 \%$ \\
\hline 2 & 95 & 108 & $87,96 \%$ \\
\hline 3 & 85 & 106 & $80,19 \%$ \\
\hline 4 & 89 & 118 & $75,42 \%$ \\
\hline 5 & 67 & 81 & $82,72 \%$ \\
\hline 6 & 57 & 77 & $74,03 \%$ \\
\hline 7 & LIBUR & & \\
\hline 8 & LIBUR & & \\
\hline 9 & 117 & 146 & $80,14 \%$ \\
\hline 10 & 99 & 121 & $81,82 \%$ \\
\hline 11 & 109 & 124 & $87,90 \%$ \\
\hline 12 & 47 & 74 & $63,51 \%$ \\
\hline 13 & 52 & 67 & $77,61 \%$ \\
\hline 14 & LIBUR & & \\
\hline 15 & 128 & 164 & $78,05 \%$ \\
\hline 16 & 98 & 122 & $80,33 \%$ \\
\hline 17 & 74 & 110 & $67,27 \%$ \\
\hline 18 & 111 & 132 & $84,09 \%$ \\
\hline 19 & 62 & 83 & $74,70 \%$ \\
\hline 20 & 47 & 63 & $74,60 \%$ \\
\hline 21 & LIBUR & & \\
\hline 22 & 133 & 176 & $75,57 \%$ \\
\hline 23 & 114 & 144 & $79,17 \%$ \\
\hline 24 & 111 & 142 & $78,17 \%$ \\
\hline 25 & LIBUR & & \\
\hline 26 & 68 & 89 & $76,40 \%$ \\
\hline 27 & 64 & 81 & $79,01 \%$ \\
\hline 28 & LIBUR & & \\
\hline 29 & LIBUR & & \\
\hline 30 & 213 & 269 & $79,18 \%$ \\
\hline \multirow[t]{2}{*}{31} & 119 & 150 & $79,33 \%$ \\
\hline & & Rata-rata keterjaringan resep $\mathrm{RJU}$ & $77,93 \%$ \\
\hline
\end{tabular}

Hasil keterjaringan pasien di satelit farmasi rawat jalan ASKES adalah:

Tabel II. Data Keterjaringan Pasien Rawat Jalan ASKES di IFRS X Purwokerto

\begin{tabular}{|c|c|c|c|}
\hline Tgl & $\begin{array}{c}\text { Jumlah resep yang } \\
\text { dilayani }(A)\end{array}$ & $\begin{array}{l}\text { Jumlah pasien yang } \\
\text { mendapatkan resep (B) }\end{array}$ & $\%(\mathrm{~A} / \mathrm{B} \times 100)$ \\
\hline 1 & 230 & 293 & $78,50 \%$ \\
\hline 2 & 135 & 191 & $70,68 \%$ \\
\hline 3 & 139 & 222 & $62,61 \%$ \\
\hline 4 & 139 & 233 & $59,67 \%$ \\
\hline 5 & 99 & 134 & $73,88 \%$ \\
\hline 6 & 108 & 224 & $48,21 \%$ \\
\hline 7 & LIBUR & & \\
\hline 8 & LIBUR & & \\
\hline 9 & 122 & 156 & $78,21 \%$ \\
\hline 10 & 136 & 201 & $67,66 \%$ \\
\hline 11 & 168 & 252 & $66,67 \%$ \\
\hline 12 & 68 & 102 & $66,67 \%$ \\
\hline 13 & 121 & 180 & $67,22 \%$ \\
\hline 14 & LIBUR & & \\
\hline 15 & 173 & 244 & $70,90 \%$ \\
\hline 16 & 129 & 187 & $68,98 \%$ \\
\hline 17 & 154 & 250 & $61,60 \%$ \\
\hline 18 & 175 & 234 & $74,79 \%$ \\
\hline 19 & 62 & 96 & $64,58 \%$ \\
\hline 20 & 92 & 141 & $65,25 \%$ \\
\hline 21 & LIBUR & & \\
\hline 22 & 187 & 287 & $65,16 \%$ \\
\hline 23 & 177 & 275 & $64,36 \%$ \\
\hline 24 & 223 & 353 & $63,17 \%$ \\
\hline 25 & LIBUR & & \\
\hline 26 & 74 & 123 & $60,16 \%$ \\
\hline 27 & 122 & 202 & $60,40 \%$ \\
\hline 28 & LIBUR & & \\
\hline 29 & LIBUR & & \\
\hline 30 & 189 & 306 & $61,76 \%$ \\
\hline \multirow[t]{2}{*}{31} & 232 & 408 & $56,86 \%$ \\
\hline & & $\begin{array}{l}\text { Rata-rata keterjaringan resep } \\
\text { RJA }\end{array}$ & $65,75 \%$ \\
\hline
\end{tabular}


Dari data tersebut kemudian
diperoleh bahwa rata-rata tingkat keterjaringan pasien di Instalasi Farmasi Rawat Jalan IFRS $X$ Purwokerto adalah sebesar $71,84 \%$. Hasil tersebut masih belum optimal, sehingga pihak IFRS $X$ Purwokerto harus melakukan evaluasi diri dan perbaikan terus menerus (continous improvement) agar pendapatan rumah sakit pun dapat meningkat. Tingkat keterjaringan yang rendah juga dapat dipengaruhi oleh tingkat kepuasan pasien terhadap layanan IFRS $X$ Purwokerto. Dari Suryanegara, 2012 diketahui bahwa dari item pertanyaan survei kepuasan pasien tentang lama pelayanan resep menunjukkan hasil kepuasan hanya sebesar 38,46\%, dan dari item kejelasan pemberian obat hanya sebesar $49,45 \%$, serta dari item kenyamanan ruang tunggu sebesar 73,63\% (Suryanegara, 2012). Hal tersebut mempengaruhi pilihan dari pasien untuk menebus resep di IFRS $X$ Purwokerto ataukah di luar IFRS X Purwokerto.

Hasil wawancara dengan Kepala IFRS X Purwokerto menyatakan bahwa perlu kerja sama dari berbagai pihak yang terkait untuk meningkatkan keterjaringan pasien di IFRS X Purwokerto. Pihak struktural rumah sakit, terutama direktur rumah sakit harus memfasilitasi dengan berbagai kebijakan yang berkaitan dengan pengadaan obat, penyediaan fasilitas atau sarana dan prasarana, perbaikan SIM (Sistem Informasi Manajemen). Kebijakan terkait dengan pengadaan obat dapat mempengaruhi tingkat persediaan obat di unit layanan IFRS $X$ Purwokerto. Kebutuhan pasien dapat tidak terlayani karena persediaan obat yang kosong. Fasilitas instalasi farmasi rawat jalan IFRS terhitung sempit, terutama di rawat jalan ASKES, sehingga mobilitas pegawai terbatas, dan SDM (Sumber Daya Manusia) yang dapat ditampung juga terbatas. SIM IFRS $X$ juga harus diperbaiki agar dapat mempercepat proses pelayanan kepada pasien, pada saat penelitian berlangsung SIM IFRS $X$ sedang dalam masa transisi perbaikan. Pihak pemerintah daerah harus mendukung dengan menyediakan pendanaan dalam pengadaan obat yang lebih baik, sehingga ketersediaan obat dapat terjaga lebih baik. Proses bisnis internal IFRS $X$ Purwokerto juga harus diperbaiki, dan IFRS $X$ Purwokerto juga harus menambah SDM untuk pelayanan, di antaranya dengan cara outsourcing, selain itu juga dengan melaksanakan pelatihanpelatihan dan pembelajaran terhadap karyawan IFRS $X$ Purwokerto.

\section{KESIMPULAN}

Rata-rata tingkat keterjaringan pasien di Instalasi farmasi rawat jalan IFRS $X$ Purwokerto adalah sebesar $71,84 \%$. Peningkatan keterjaringan pasien dapat dioptimalkan dengan kerja sama dari berbagai pihak terkait, seperti pihak struktural rumah sakit, pihak pemerintah daerah, dengan pihak IFRS $X$ Purwokerto.

\section{DAFTAR PUSTAKA}

Anonim, 1999, Struktur Organisasi dan Uraian Tugas Staf Apoteker dan Karyawan Lain, Instalasi Farmasi Rumah Sakit Umum Daerah Prof. Dr. Margono Soekarjo, Purwokerto

Depkes RI, 2004, Standar Pelayanan Farmasi di Rumah Sakit, Departemen Kesehatan Republik Indonesia, Jakarta 
Kairu, E.W., Wafula, M.O., Okaka, O., Odera, O., Akerele, E.K., 2013., Effects on Balanced Scorecard on Performance of Firms in the Service Sector, European Journal of Business and Management, Volume 5 number 9, p.81-88

Kaplan R.S., Norton D.P., 1996, Balanced Scorecard: Translating Strategy Into Action, Havard Business School Press, Boston

Mulyadi, 2005 , SistemManajemenStrategikBerbasis Balanced Scorecard, UPP AMP YKPN, Yogyakarta

Mulyadi, 2008, Balanced Scorecard as A Core of Strategic Management System ppt. www.usd.ac.id/createpdf/php

Okwo, I.M., Marire, I.M., Performance Measurement in Business Organizations: An Empirical Analysis of The Financial Performance in Some Breweries in Nigeria, Research Journal of Finance and Accounting, Volume 3 number 11, p.48-57

Suryanegara, F.D.A., 2012, Analisis Kepuasan Pasien Rawat Jalan Instalasi Farmasi RSUD Prof. Dr. Margono Soekarjo Purwokerto, Jurnal Medicoeticolegal dan Manajemen Rumah Sakit, Vol.1 No.1, p.114-121 